\title{
Assistive Technology in the Public Schools
}

\author{
M. Shannon McCord
}

\author{
Pajaro Valley Unified School District, Special Education Department, \\ Watsonville, CA 95076 USA
}

\begin{abstract}
Providing assistive technology and/or augmentative communication devi ces to students with disabilities ranging from severe cognitive delays to orthopedic handicaps can drastically increase their ability to participate to their potential in the public school system and improve self-esteem at the same time. Our Special Education Local Plan Area has established a new lab to facilitate exposing as amany students as possible to the latest technology and to provide a space for training the entire team that works with the students including the family.
\end{abstract}

\section{Introduction}

We, Shannon McCord and Valerie Benito are two specialists in the field of technology and special education who reside in Santa Cruz County, California, U.S.A.. We work in the Pajaro Valley Unified School District which is a multi-cultural, multilingual district located in central California. We are only hours from San Francisco and the technology rich silicone valley. Our diverse student population consists of 17,000 students from a wide range of ethnic backgrounds. We have programs for 2,200 special education students from 0 to 22 years of age. Many of our students come from families with limited economic resources.

The Pajaro Valley Unified School District is committed to providing appropriate inclusive educational programs for all students. We have established programs for physically disabled, hearing or visually impaired and most recently, severely emotionally disturbed and autistic children. These programs are supported by itinerant teachers who work collaboratively with general education teachers to facilitate the mainstreaming of special education students with unique needs. This allows us to serve the majority of our students in their neighborhood schools.

\section{Overview of Assistive Technology Program}

\section{Purpose}

The Pajaro Valley Unified School District (PVUSD) recognizes that one of the barriers to equal access for all students is the availability of technology in the classrooms. Students with special needs often require the use of assistive technology devices to reach their full potential in general education classrooms. The provision of assistive devices aides in increasing communication, mobility, and independence in daily living skills for many students. Collaboration between parents and teachers in the use of assistive devices for children with special needs also significantly modifies the class learning environment so that segregated placements for individuals with severe disabilities no longer needs to be the norm.

Our full inclusion programs are successful, in part, because the district uses assistive technology to supplement and support the curriculum. The staff and administration of PVUSD realizes that, in order to create schools where all students 
flourish in their natural settings, it is necessary to take full advantage of the current technological advances that are making the world more accessible to all people today.

The recently established Assistive Technology Program is the vehicle by which PVUSD meets the technical needs of our special education students. The following Concept Attainment data set will help the audience to understand our purpose by categorizing the terms:

\begin{tabular}{ll} 
YES (Access to devices) & NO (Without access) \\
\hline -Independent Living & -Isolation \\
-Communication & -Dependence \\
-Establishing Peer Relationships & -Misunderstood \\
-Increase self-esteem & -Negative Personal Regard \\
-Increase Performance & -Communicate personal needs only \\
-Develop fine and gross motor skills & -Unable to complete assignments \\
-Computers & -writing skills to assess potential
\end{tabular}

\section{Augmentative Communication and Assistive Technology Lab}

\section{Components}

We will use an Inductive Lesson Data Set to have the audience explore the materials and discover the categories of our lab. The set includes:

-Wheelchair mounting bar

-Switch Kit

-Augmentative Communication Devices

-Computer Training Program

-Books, Catalogs

-TDD

-Language Games

-Community Skills Cards

The participants will look at the material and list the attributes of each one. They will then discuss the attributes in a small group and discover the common themes. This will help them find that we have organized our lab into the four following areas:
A. Assessment
B. Training of students, staff, and parents
C. Resource Area
D. Social/Pragmatic Area

\section{Conclusion}

In conclusion, we would like to explain the benefits that we have seen from having a specialist and a lab available in the district. It is not only the special education students who benefit from the use of the equipment. The general education students, school support staff (secretary, custodian) and teachers all benefit from the experience of having a more diverse student population. In the long nun, all of society will benefit from seeing that more people can be productive members of society. We would like to share some personal stories of the people whose lives were affected. [Read quotations and excerpts from collected stories.] 
One amazing example of the way technology can enrich the lives of people with significant disabilities is a demonstration of "Switch Ensemble". This is a music based program that allows students with severe cognitive and/or physical delays to perform high quality concerts independently. [Video and hands-on experience.] 